\title{
Development versus Environment
}

\author{
Dr. K R. Sinha ${ }^{1}$, Ms. C. L. Nongpluh ${ }^{2}$. \\ ${ }^{1}$ Department of Geography, Saint Mary's College, Shillong, India. \\ ${ }^{2}$ Department of Geography, Saint Mary's College, Shillong, India.
}

\begin{abstract}
Natural Environment faces tremendous stress due to developmental activities in general and that of infrastructural development in particular. Such infrastructural activities involve clearing of forests, cutting off hill/ mountain sides and encroaching on cultivable or cultural land, and consequent loss of biological diversity. The broadening of the existing National Highway no. 40 and the construction of the Shillong By Pass has resulted in tremendous stress to the fragile environment of the hill state of Meghalaya, India. The article is based on observation and first hand information.
\end{abstract}

Key words: Development, Environment, Fragile, Meghalaya, Stress.

\subsection{Nature of the Problem}

\section{Introduction}

The last 200 years has been a time of massive ecological change driven by economic expansionbringing changes to lifestyles and more importantly, creating new ecological systems. The continuous effort not just to create livelihoods, but to also make life more comfortable has driven man to explore end exploit the environment and its resources. In this, man has been aided by technology.

Economic expansion in the race for development has had destructive impacts on existing ecosystems. Man's capacity for destructiveness is not just the outcome of modern technology. Man has been altering the environment from the beginning, when he set fire to the forest either to kill herds of animals or clear forests for crop cultivation. Man has even hunted down entire species of animals to extinction. Thus, traditional as well as modern societies have had devastating impacts on the ecosystem. However, the scale and rate of such devastation have never been as tremendous as at present when modern men armed with modern technology have brought mass destruction of ecosystems. Transportation and expansion of transport network has been responsible to a large extent in bringing about environmental change (read damage). Thus, the natural habitats and wildlife are disappearing or are under threat of disappearing in the pretext of development.

\subsection{Previous work}

Geographical studies, as with Ratzel's Anthropographie, moved through environmental determinism and possibilism to anthropogenic changes- the manner and circumstances by which people created livelihoods embedded in landscapes. Carl Sauer, another geographer, reviewed the destructive impact of human activities on ecological processes. He marked three areas of loss- the extinction of species and varietal forms; loss of habitat and range; and destruction of soil's function as a location of essential ecological and hydrological processes. ${ }^{1}$

Developmental activities and the resultant ecological conflicts have attracted attention from Madhav Gadgil and Ramachandra Guha who have focused on the increased frequency and intensity in nature- based conflicts in India. They have noted that from the ecological perspective the high incidence of water logging and submergence of forests are unacceptable cost of dam building. The social implications of displacements of millions of people without properly being rehabilitated has been recognised as one of the causes of environmental movements. ${ }^{2}$

\subsection{Purpose of the article}

The neo- classical economic view that continued growth is necessary for continued prosperity is opposed to the ecological economic viewpoint which acknowledges the importance of ecosystems function for continuation of human ecosystems. Ecosystems services cannot be measured in monetary terms. Therefore, the purpose of the article is to focus on the conflict between development and the consequent environmental damage.

The purpose of the article is also to bring to focus the scale of environmental damage, and loss of ecosystems as a consequence of development by way of expansion of NH. 40, and its By-Pass in the Ri- Bhoi and East Khasi Hills districts of Meghalaya. 
As cost- benefit analysis (CBA) alone of such economic expansion is not sufficient, the article will attempt to draw attention of the decision makers to the need for engaging in a natural resource accounting as well which would mean consideration of the non- monetary cost of ecological damage and loss of ecological services.

\section{Observations And Conclusion}

\subsection{Advantages and limitations of the project}

The National Highway 40 connects Shillong to Guwahati, and via its By-Pass connects Jowai and beyond, connecting the Barak Valley region of Assam and Tripura, Mizoram as well as Western parts of Manipur. Thus, this Highway is the economic lifeline connecting all these regions to the rest of the country.

Needless to say there is a continuous stream of busy traffic along the Highway transporting much needed commodities including food grains and medicines, given the fact that other modes of transport are either nonexistent or poorly developed. Thus, the felt need to broaden this vital life- line to facilitate ease in movement of traffic as part of the economic development within the region.

National Highway Authority of India (NHAI) undertook the development of the highway by way of converting the stretch between Guwahati- Shillong to 4 lanes from the earlier 2 lane roadway. Fund for the project was sanctioned in the 1990's. The execution of the project was handed over to M/S IL \& FS Transportation Network Ltd, Mumbai and M/S Ramky Infrastructure Ltd, Hyderabad (JV) for NH 40, and M/S GR- Chetak, Udaipur (JV) for 2-Laning the By- pass (National Highway 40 \& 44). Total cost of the entire stretch (61.80 km for 4-Laning, and $48.76 \mathrm{~km}$ of 2-Laning) was Rs 762.00 Crores. Work started over three years back (which began towards the end of 2010).

The potential benefits of such a project includes:

- Reduced time in travel- speedy and uninterrupted flow of essential commodities to Shillong, places in Jaintia Hills in Meghalaya, Barak Valley, Tripura, Mizoram and parts of Manipur.

- Reduced fuel consumption (distance between Umroi and Mawryngkneng is reduced by about $12 \mathrm{kms}$. Via the By- Pass. This implies reduction in fuel consumption particularly for heavy vehicles by 2 to 3 litres per vehicle for this given stretch).

The economic cost, apart from cost of technology/ capital, labour, compensation paid, etc. include:

- Reduced farmlands- hill slopes adjacent to the Highway which were devoted to cash crop farming (pineapples, ginger, rubber, and even tea) were excavated for road expansion. At the same time paddy fields on the lower slopes and valleys lying adjacent to the highway were destroyed as excavated soil, boulders, debris etc. were dumped on the fields.

- Food insecurity- reduced farmland and resultant landlessness compromises the food security of the affected households.

- Loss of livelihood- farmers with farmlands along the Highway face loss of livelihood.

- Loss of small trade- as road expansion has progressed, many of the petty traders who had set up shop along the highway were affected.

Cost-Benefit Analysis of the project undoubtedly will find that the benefits of the project outweighs the monetary cost of the project, including compensation paid to communities/ villagers/ farmers affected by the project. But the non- monetary cost of ecological damage and loss of ecological services has not been accounted for. What is also missing is natural resource accounting which is conveniently externalized.

The environmental cost which is the non-monetary cost of the project would include loss of habitat for the flora and fauna of the fragile ecosystems characterised by many endemic species. These hills also provided habitat to unique tribal societies following cultures rooted in nature. The roadways development pose threat to such cultures as also loss of livelihoods. Also there is threat to increased soil erosion and attendant problems as also destruction of soil's function as a location of essential ecological and hydrological processes, apart from reduction in ecological services and air and water pollution.

Apart from the above, the impact on the health- of people living in the adjacent areas, as also of the plant life cannot be overlooked. The thick blanket of dust which hangs over the entire stretch of ongoing project affects the villagers and plants and animals alike. A casual conversion with residents living near the highwayexpansion project revealed an increase in respiratory problems amongst the these residents which perhaps could be attributed to the increased dust particles associated with excavation of the hill slopes and deforestation. Evidently, the environmental viability of such a project is questionable. Although not quantifiable in monetary terms, the non-monetary cost seems to far outweigh the benefits of the project.

\subsection{Application of the article}

It can be noted that for growth and economic development environmental sustainability has been compromised. In a state which is already losing its forest cover rapidly, this project further worsens the situation. The importance of the article lies in the fact that while decision makers try to justify the project on the grounds that such a development is essential whatever the cost, especially when other means of transport is 
limited or non- existent, it will hopefully bring awareness about the gravity of the loss to environment and would compel decision makers to explore more sustainable mode(s) of development. Awareness can be generated amongst the public which could help in mobilizing action for a more sustainable mode of development. The article can also serve as the basis for an in-depth research of the cost-benefit analysis of the development project. The article also opens up scope for research on the extent of health hazards to the villages due to the lowered quality of air and water, the extent of loss of livelihood, and the socio- economic consequence of such a loss. There is also scope for research on changing ecosystems consequent of such interference.

\section{References}

[1]. Sauer, C. O., Plant and Animal destruction in Economic History, Journal of Farms Economics, 1938 20: $765-775$

[2]. Gadgil, M. and Guha, R., Ecological Conflicts and The Environmental Movement in India, in Rangarajan, M (ed), Environmental Issues in India- A Reader, Delhi: Pearson Longman, 2007 pgs 385- 428 